dress which concerned the welfare of the American Chemical Society and the publication of its Journal:

Those engaged in industrial pursuits must always remember that although they equal in number the educators and other students, or may even form a majority of the society, it is none the less true that the former are, and no doubt will continue to be, the greater producers of new and original matters, and hence deserving of greater consideration in proportion to their numbers than those who are less productive.

Any one who has had an opportunity to review the new and original work being done in industrial fields cannot help but feel aprofound admiration and respect for the high-grade research work which forms the basis and the immediate means of realization of much of the industrial progress on which the present age prides itself. While the writer does not assume authority to reply for all industrial chemists, he believes that if they were not restricted by commercial policies of secrecy, their publications of new and original scientific work would be just as numerous, and quite as valuable, as those of their unrestricted brothers in the educational laboratories. Investigation work carried out to meet industrial needs may be, and frequently is, as distinctly scientific as that which is done to fulfil the requirements of a doctor's thesis.

This attitude of chemistry teachers toward the industrial field is shown by the fact that a large majority of students taking advanced graduate work have done so in preparation for teaching positions. But that graduate work is not merely a means of getting into educational work is demonstrated by the large and increasing numbers in the graduate departments of our engineering schools, who are looking forward to industrial pursuits.

In conclusion, the writer asserts his belief that there is in general an inefficiency in the college training of men for industrial chemistry; that this training is largely in the hands of men who have an insufficient acquaintance with and appreciation of the requirements of the industrial workers; and that when educational chemists and industrial chemists finally come together on common ground, some of the present difficult educational problems will disappear.

DEPARTMENT OF CGEMICAL ENGINEERING, UNIVERSITY OR WISCONSIN

\title{
A LABORATORY COURSE OF CHEMICAL ENGINEERING.
}

BY WILLIAM $H$. WALKER AND WARREN $\mathrm{K}$, LEWIS

In order that the suggestions as to the make-up of a course of Chemical Engineering contained in this paper may be as concrete as possible, we have made a number of assumptions which it will be well to state at the outset. First, the work here outlined is intended to form a part of a fouryear course such as is given in our engineering schools, and no attempt 
has been made to even discuss matter which should be taken up in a fifth year, however desirable such matter may be. Second, the course here presented is designed for that class of students that hopes upon graduation to be in position to accept employment in any line of chemical industry, rather than those who by becoming relatively expert in one industry are thereby limited to that particular field. Third, that students taking the course here outlined shall have had an adequate training in the fundamental subdivisions of chemistry, including descriptive industrial chemistry, and the essentials of physics, mechanics, and thermodynamics. Finally we make the assumption that the future employers of the men so trained are willing and, in fact, expect to teach these men the details of the particular work for which they are employed.

While we do not depreciate the good work of the trade schools, nor do we fail to recognize the opportunities open to the graduates of such schools, we believe that a training that devotes so large an amount of time in a four-year course to the details of the manufacture of one industry cannot produce the man to whom that industry must look for its final improvement and progress. The reason for this seems obvious; no school can teach much concerning soap making for example, which is not already known as a part of this art. Hence the very best that can be done is to turn out a soap maker who knows all that is now known about this particular industry. He has not obtained and cannot get in a four-year course, that sound general knowledge of the principles of chemistry in its broadest sense, or the fundamental concepts of engineering; he knows only those principles which are involved in soap making. But to solve the problems in soap making requires knowledge other than that already applied to this industry; were this not so these problems would have been solved long ago.

Hence we believe our last assumption to be a sound one, namely, that the employer should and must expect in taking on a new man fresh from an engineering school, to teach him the factory details of the work for which he is employed, in order that he may get a man with the breadth of knowledge necessary to his best interests. When such a man has learned the practice of soap making or tanning from capable foremen in the factory and is then brought face to face with the problems which exist there, he is able to climb into the conning tower as it were, take a survey over the entire field, and as a result bring to bear upon the solution of the problem, the principles of chemistry and engineering which, although possibly applied to other arts, are also applicable here. He does this in a way that an expert in that particular industry alone, but deficient in general scientific training, can never do.

It is but a truism to day that our chemical engineer should have adequate training in a laboratory of chemical engineering. Doctors 
of medicin have hospital clinics, mining engineers their laboratories, and why not then a laboratory of chemical engineering. But of what will it consist, and how will it attempt to teach the things the men most need to know?

The choice of suitable experiments for such a course may be aided by the consideration of a few general principles:

I. The student must be given some idea of the factors which enter into the economy of a process. Although he has had both organic and inorganic preparations this work was taken up from an entirely different point of view. He does not appreciate, for example, that boiling off water is expensive, or that a process may, on account of special conditions imposed, be more expensive to operate at a high chemical efficiency, than when the reaction is allowed to proceed at a lower efficiency. The study of a reaction for itself is the function of the laboratory of general organic or inorganic chemistry; the details of factory practice can best be learned in a factory; but an economic point of view can not be learned in the first, and should be acquired before the student enters the second.

2. The experiments selected should be those which typify some important fundamental principles, and in which these principles can be made to stand out in strong relief; there is always danger of covering up the principle with the details of an operation.

3. The experiment should be one that admits of theoretical discussion. One of the greatest difficulties that a teacher has is to get his students to use their knowledge of theoretical or general chemistry or physics in their engineering laboratory work. The more completely and accurately, therefore, that the results of variations in the conditions of an experiment can be predicted before the experiment is begun the more valuable it is. It is also desirable that these modifications or variations of conditions be involved in the plan of the experiment, in order that what may be called the "spirit of research," or thesis idea, may be introduced into the class work. That "research" should be rigorously delegated to special men in specially equipped labotatories is a basic error which can do much harm in educational work. While valuable results can, in general, be obtained by only more highly trained men working through consecutive hours for a considerable time, yet the spirit of investigation can be introduced into a great deal of our more advanced laboratory work. It is possible to divide the class into groups, and so plan the conditions of the experiment that each group will contribute, by the average of their individual results, to the solution of the problem as a whole.

4. And, possibly most important of all, the experiment must admit of reasonably accurate work. Nothing is more nearly fatal to laboratory success than to choose, as experiments, processes which cannot be held 
sufficiently under control to make concordant results possible from each member or group of members of the class.

The following series of experiments illustrate the kind of work which has been found instructive in the laboratory of the Massachusetts Institute of Technology and are offered here merely as suggestions.

I. One of us has published ${ }^{1}$ in considerable detail a laboratory experiment on the electrolysis of brine which is well calculated to familiarize the student with the industrial significance of electricity when used as a chemical reagent. The relation of amperes, watts, coulombs, etc., to the cost of the resultant product is here brought out in a way that gives the student working grasp of these unit quantities obtained only in such a way as this.

2. Almost every industrial chemical laboratory will have a steamjacketed kettle of some sort in its equipment but how much does a student usually gain from such a piece of apparatus? He makes in it, let us say, a batch of soap. The chances are that the product will be poor and the cost high; even under the instruction of an expert soap maker, he will learn, at best, only how soap is made. But his power to solve problems in chemical engineering has not thereby been increased.

With even so simple an apparatus, however, the principles of the application of heat to liquids may be well illustrated. Let the student measure the pressure of the steam and, by means of a throttling calorimeter, its quality as it enters the jacket and determin the amount used by weighing the condensed water. From these data he can calculate the total heat consumption of the apparatus. He can determin the amount of water evaporated at definit time intervals by measuring the increased concentration of the solution by either titraticn or specific gravity. He can thus obtain the heat consumption per pound of evaporation, determin the efficiency of evaporation and the heat losses. By using different solutions the variation of the heat of vaporization may be emphasized. He can determin the heating surface necessary for a given rate of evaporation and study the efficiency of lagging material. By substituting for the steam-jacketed kettle a barrel with a steam coil of known dimensions other variations may be introduced. Although the student may have worked with small and inefficient apparatus, he leaves the work with a vital grasp of the principles of the application of heat to liquids.

3. In connection with the previous experiment the uneconomical nature cf open pan evaporation will be emphasized by the analysis of the heat losses. This leads to the problem of multiple-effect evaporation which is of such great and growing importance in chemical industry. If the laboratory of chemical engineering is to ape industrial conditions

\footnotetext{
1 Proceedings Electrochemical Society, 9, 23.
} 
and show the student only the best practice in carrying out a given operation it should be equipped with a complete triple or quadruple effect evaporator. We would, however, advise against this installation. More efficient instruction can be given by use of a single-effect apparatus, designed to stand either pressure or vacuum, and fed with boiler steam through a reducing valve, capable of close regulation. The problem of the man ufacture of caustic soda, involving as it does a nice cost balance between the expense incurred in concentrating weak caustic liquor and the incompleteness with which the causticizing reaction may be effected in a concentrated solution, is well adapted to this work. A run is first made using the highest feasible steam pressure, determining the steam consumption, evaporation, and the pressure of the steam from the evaporating liquid. Then a second run is made in which the steam pressure from the boiler is reduced to the value found for the steam generated by the solution in the previous run. Later a vacuum is maintained and thus through the manipulation of a single effect the data may be obtained which will give the student a more vivid idea of the design and operation of a multiple effect than the use of a multiple-effect unit itself can produce.

4. In chemical industry grinding and pulverizing is usually undertaken to hasten chemical reaction. This is a surface action and its rate is consequently proportional to the total exposed surface of the solid. The useful work done in pulverization can be measured therefore by the surface produced, and the cost of operation may be expressed per unit increase in area. It is, of course, impossible to accurately measure the total area of a mass of small particles, but a number which is p1oportional to it may be determined as follows: separate the material coming from the mill by either screens, settling, air separation, or other means, into a series of fractions, the mean diameter of particles in each of which is estimated (for example by measuring the screen opening). Knowing the specific gravity of the substance the weight and surface of each particle may be calculated, and knowing the weight of each fraction of the mill product, the total surface of each fraction may be obtained. The sum of the surfaces of all the fractions is the total surface exposed, and the difference between this and the total sturface before the grinding measures the efficiency of the grinding operation. The application of this idea to ball mill work shows the increase in surface as a function of the time for any given conditions such as size of mill, rate of rotation, size of ball, etc., and indicates the influence which varying these conditions has upon the efficiency of the mill.

5. In the minds of most students the term "solubility table" is inextricably involved with "solubility product" or some other concept usually employed only in theoretical work. A problem in crystallization, 
fractional or otherwise, carefully planned and checked by utilization of published solubility tables clears up this misconception. The preparation of barium nitrate from Chile saltpeter and barium chloride offers an excellent opportunity to show how the solvent may be evapcrated until just enough remains to hold the more soluble salt in solution after cooling. It is possible by use of data already published to separate the barium nitrate from the sodium chloride, and a problem of this sort where calculated results are checked by careful experimental work gives a thorough grasp on the principles of separation through crystallization.

6. Another problem of large importance which illustrates the phenomena of heat transfer as well as the practical applicability of the laws of heterogeneous equilibria is that of distillation. That work in a modern distillation plant, while it familiarizes one with the best industrial practice, can entirely fail to make clear the principles involved, is shown by the fact that most distillers, though goud engineers, thoroughly versed in the technic of their trade, can give no qualitative explanation of the heat and concentration changes taking place in their own columns, and are unable to follow and check these changes quantitatively. The rectification of aqueous ammonia in a small plate column makes a very instructive experiment. The composition of the entering mixture, the liquid on each plate, the distillate, the slop or refuse, and the heat consumption, may be measured. The operator will determin the heat extracted by the cooling water and the composition of the partial condensate. With this data he can calculate the actual heat consumption per pound of distillate, the percentage heat efficiency of the operation, the heat transference constants of his different surfaces, the heat losses, and thus obtain the necessary information for any desired modification of the tower or still. Such an experiment shows not only how a rectifier works but why it does so, and enables him to intelligently design and control apparatus of this type.

These are but suggestions of the kind of work which we believe can be taken up in a laboratory of very modest equipment. Many others, as well as modifications of these will quickly suggest themselves to those interested in this kind of instruction. One further feature of the work which we consider very important is the preparation of a written report upon some problem, the solution of which has been attempted in the laboratory. This is not simply a recalculation or working up of data obtained during an experiment, or a more or less verbatim copy of the laboratory notes but a logical, critical, and as far as possible, convincing digest of the proposition as seen in the light of the laboratory work. The ability to write up laboratory notes in a tangible, readable, easily-getat-able form is so uncommon with our engineering students that any exercise which stengthens his command of English is of great value. 
Every report should be so prepared both as to its English and its mechanical get-up, that it will appeal to, and be read by the busy man at once, and not be laid aside for the leisure hour which never comes.

Such a course as here outlined will never take the place of the instruction which must be obtained in a factory or works, and will not make a finished engineer; but it will contribute mightily toward giving that method of thought and work which produces the man "who knows what to do when there is something to be done."

Massachusetrs Institute of Technology, Boston, Mass.

\section{POINTS OF VIEW IN THE TEACHING OF INDUSTRIAL CHEMISTRY. By James R. Withrow. Received January 3, 1910.}

When Prof. Talbot's kind invitation to present a paper on some phase of the Teaching of Industrial Chemistry was accepted it was done with a frank statement that the author would not have time to give this presentation the careful thought which the subject merits. The real object, therefore, of the author of these words is to get acquainted with the point of view of those who are contributing to this meeting whether on the program or helping in the discussion. He is of course glad to contribute his mite if it can assist in any way toward the desired end. After a few. preliminary remarks, therefore, attention will merely be called to a few points of view in the Teaching of Industrial Chemistry which have been found of service under the conditions among which the speaker finds himself.

In a discussion of the teaching of any subject there would probably be almost as many opinions expressed as there were teachers present. If this is true of any subject it must be peculiarly possible in the case of Industrial Chemistry because of the well known magnitude of the range of the application of chemistry to the industries. It seems that what differences of opinion may exist among teachers of this subject are largely due to the fact that individual experience has differed so much, the range of possible experience being so great.

In the Teaching of Industrial Chemistry as in probably every other subject the problem which presents itself to the teacher may be summed up in the two questions:

What shall I teach?

How shall I teach it?

Ignoring the first in the brief time at hand with the assumption that what is meant in our topic by Industrial Chemistry is the study of the manufacture of chemical substances or the manufacture of commercial products with the aid of chemical processes, the present remarks will be confined merely to a few points of view with reference to the How. 